\title{
Comparing BMI and hand grip strength of Tsinghua University Beijing and University of Sindh Pakistan students
}

\author{
Muhammad Rafique, Prof. Zhang Bing, Muhammad Akram Ansari, \\ Javed Ali Soomro, Ashok kumar Chuohan, Sunzhongwei, \\ Key Sports and Health Research Center School of Social Science Tsinghua University Beijing China
}

\begin{abstract}
Background: This study was an illustrated cross sessional study of male and female students of Tsinghua University Beijing China and University of Sindh Pakistan students. The study objectives were to describe normative data and compare the BMI and hand grip strength of dominant hand of both universities students. The study elaborated that health and fitness status of universities lifestyle of young male and female students are significantly related to the desire level of general health and fitness level and observed the attitude of students towards health assessment activities and status.
\end{abstract}

Method: The sample was selected of both universities overall 600 students, ranging in age of 18-23 years. There were 150 male and 150 female healthy students of each university were participated. Both university students were compared their BMI and HGS of dominant hand. The strength was measured with STF calibrated hand grip dynamometer and used the normative criterion of general grip strength of franklin 2000 to calculate the result. All the conclusions were described by SPSS 20 and MS excel 2010.

Results: The study population was relatively young and they were classified in three interval groups'. The mean of TUBC and UOSP BMI (23.72 - 23.34 male, 21.19-22.21 female, 22.45 -22.77 MF) and std. deviation (3.72 - 4.22 male, 2.83 - 3.46 female, 3.53 - 3.89 MF) $t$-value TUBC 110.16 and UOSP 103.38 and $p$-value is 0.001 significance. HGS mean (46.35 - 45.07 male $30.87-29.30$ female $38.61-37.18 \mathrm{MF}$ ) and Std. deviation (9.16 -8.30 male, 5.32-'4.94 female10.77-10.43 MF) and t-value TUBC 62.07 and UOSP $61.73 p$-value is 0.001 significance $<0.05$. The average difference of BMI of TUBC and UOSP $(67 \%-64 \%$ normal, $18 \%-23 \%$ overweight 10\% - 7\% underweight and 4\% - 6\% MF were obese. The prevalence of BMI>25 overweight and $>30$ overall obesity of UOSP were higher than TUBC students. The correlation of BMI and HGS is significance of 0.05 levels. In HGS the performance of both universities performance was satisfactory. While, the females HGS performance of TUBC were higher and better then UOSP students.

Conclusions The research innovative of health and fitness should create an atmosphere of general health assessment and identify their strength and weakness. To highlight their physical and physiological competencies motivated them healthy, foster and active lifestyle in their routine living. To freshman the HFA attitude of university students and were produced normative evaluation infrastructure for future research. The Overall goals of research study are to benefit to the general public particularly the university students.

Keyword: BMI, Grip strength, Health, Fitness, normative data, attitude, assessment.

\section{Background}

The mounting prevalence of obesity in the younger adult population of every nation is a sheer concern hence the vitality of assessing the body fat has been a renaissance of interest in the appraisal of different body composition approaches (Gruber and Kitano, 2001) ${ }^{1}$. The World Health Organization (WHO) expresses overweight and obesity on BMI at $>25$ and $<30 \mathrm{~kg} / \mathrm{hm} 2$ respectively in younger adult populations (WHO, $1995)^{2}$. However, there is increasing evidence that these cut-off values are not effective for all populations (Luke, 1997; Durenberger, 1998; Durenberger and Yap, 2000) as the connection between BMI and body fat percentage fluctuates between populace groups. Additionally, it is the quantity of physique plump, rather than the sum of excess weight, that regulates the health risks of obesity (WHO, 1998) ${ }^{3}$. This is clarified the cumulative interest of research scientists and the general public in body fat assessments. Obesity has become a major health, social and economic burden of today's world (James, 2004) ${ }^{4}$. It has now been well established that obesity directly increases cardio metabolic risk by altering the secretion of adipocytes and indirectly by promoting insulin resistance and its associated metabolic disorders such as Type-2 diabetes. Moreover, obesity causes additional health problems as it is closely associated with the development and progression of coronary heart disease, certain forms of cancer, respiratory complications (e.g. obstructive sleep apnea) and osteoarthritis (Kopelman, 2000) ${ }^{5}$. On the other end the Muscle weakness, low body weight, and chronic diseases are often observed in the younger adult people; however, the association of muscle strength with mortality, independent of disease status and body weight, has not been elucidated. Although there are several methods to estimate BMI, there is no 'gold standard' for both epidemiological studies and personal use. The main objective of the research 
is to develop the health and fitness assessment attitude and motivate the students towards this practice. The research would highlight the strength and weakness of 18-23 years of age subjects by HFA process. Generally this age group of adults has been largely ignored. Keeping in view that BMI and hand grip strength (HGS) are assessed as predictor of mortality and other health problematic diseases within this age group. Initially healthy and disease-free young adult students of Tsinghua University Beijing China TUBC and University of Sindh Pakistan UOSP were evaluated to compare the normative data of BMI and dominant hand grip strength of 18 23 years adult students. The major goals of study were to develop an attitude of fitness assessment in the university students and also compare general fitness attitude of the students of both nations. The inquiry consisted of general health and fitness status of students of both universities. In this connection various related studies were reviewed and vitality of two nations' general health problem was kept in mind. Strength capabilities of the young students have been decreasing day by day along with an increase in obesity in general public. This triggers various physiological problems affected general health. Despite considerable attention to adverse effects of obesity on health, it has not shown any diminishing trend in society in general. The recent survey of ten provinces in china indicated that $34.4 \%$ of adult population aged 20 -39 years were overweight. Another study on more than 43000 adults aged 20 to 39 years shows that 11 percent of these people are obese 2 percent more than the last survey in 2010. (General administration of sport survey, 2010) ${ }^{6}$ In Pakistan, according to World Health Organization (WHO) estimates 19 percent of men and 26 percent of women are obese having BMI greater than 25 but only 1 percent of men and 4 percent of women are documented as obese using the standard criteria of having BMI greater than 30. The prevalence of obesity is even higher in urban areas $(56 \%$ in men and $67 \%$ in women). A recent study showed high rates of underestimation of overweight and obesity among Pakistanis i.e. $52 \%$ of overweight and $73 \%$ of obese people thought they were normal ${ }^{7}$. Appropriate perception of weight status and awareness of the dangers of obesity and the benefits of weight loss are a prerequisite for weight loss efforts and its success ${ }^{8}$. Guidance given to obese people to lose weight may go unheeded if they consider themselves normal weight. The health and fitness implications of obesity are epidemically hard to quantify and predict although it is cleared that obesity and strength weakness conditions have become one of our greatest health challenges for younger population. Since similar trends were evident in almost all the developed and under developing countries, the younger population's poor muscle strength has been found to be concomitant with lower body weight ${ }^{9}$ resulting in the presence of chronic diseases ${ }^{10}$, physical inactivity and eventually lower education ${ }^{11}$ and well-being. All these factors are the known predictors of increased mortality ${ }^{12}$. However muscle strength itself as a predictor of mortality has been addressed in only a few studies, with follow-up intervals of no longer than 6 years. ${ }^{13}$ In middle-aged men followed for 6 years, the risk of mortality was more than two times greater among those in the lower half of grip strength than those of higher half of grip strength. ${ }^{14}$ Among 75 year old men and women, poor strength tested in multiple muscle groups predicted increased mortality over a follow-up of 4 to 5 years. ${ }^{15}$ These studies suggest that good strength is an important predictor of survival.

\subsection{Subject Participants}

\section{Methodology}

The random samples of 600 students were selected from both universities, aged between 18-23 years. There were 150 male and 150 female students of each university who participated. The data was collected during March 2012 for the collaborative partial support project between TUBC and UOSP. Both university students were compared with respect to their BMI and HGS of dominant hand. The strength was measured with calibrated hand grip dynamometer and used the normative scale of general grip strength of franklin 2000 to calculate the result. All the conclusions were described by SPSS 20 and MS excel 2010.

Protocols of human health metrics were used as per study requirements and approved by the both university's research studies committees (URSC) as part of the investigation. The informed consent and PAR-Q forms were filled by both university students. The idea was to get harmonized with the population of healthy subjects in order to obtain an optimal BMI and hand grip strength data. The BMI assessed this way is more widely used and accepted because values correlate better with measures of body fatness. BMI was mathematically calculated with a general Quetelet index formula of BMI=Weight $\left.(\mathrm{kg}) / \mathrm{heightm}^{2}\right)$. This formula requires the weight in $\mathrm{kg}$ and height meter square of the participant to get the BMI. Using the international normal scale of BMI one can calculate the percentage of body fat of the subject.

The norm of BMI has universally standardized by WHO and researchers for the calculation and conclusion. On the other end the American Society for Surgery of the Hand (ASSH) and the American Society of Hand Therapists (ASHT) ${ }^{16}$ have standardized positioning, instruction and calculation of HGS. The vitality of ASSH assessment of hand grip strength had been evaluated. The assessment of strength test by the stationary force is pragmatic wherein the dominant hand could be clutch on a hand grip dynamometer where the force has most normally been measured in kilograms. The ASSH process of HGS assessment ${ }^{17}$ is a reliable appraisal and identical method in strength test. There are diverse evaluators available and different devices of dynamometers 
of strength assessment and also diversity of methods of positioning used to measure. ${ }^{18}$ In figure $1-4$ the STF dynamometer calibrated device was utilized to evaluate the dominant hand strength. During the assessments of strength, we had used the proper protocols and procedures of tests. There were three trails conducted out of these the best trail had been taken into consideration.

The published normative data of hand grip strength is available from different countries. They are still carrying out research to discover fresh research information. It is a first research of this kind to escalate the fitness assessment attitude in the student's community in Pakistan. The study of this kind is a representative of trends in developed nations. Some studies divided participants by right and left hand and while others by age or gender but a small number of studies divided participants by age gender and also with respect to the dominant and nondominant hand. HGS is predictive of other health conditions, although the liaison has not been declared to be contributory. ${ }^{19}$ The longitudinal studies proposed that poor hand grip strength is prognostic of increased mortality from cardiovascular disease and cancer in males. The HGS is harmfully associated with physical infirmity along with an effect to the body mass index (BMI). The behavior of muscles could be assessed and used by hand grip dynamometer. Various scholars and scientists declared a positive relationship between BMI and HGS of both genders in all ages.

The studies were from various countries, and concerned subjects of diverse genders, ages, types of work ethnicities and access to nutrition. There is one study of HGS in Australian adults but no inquiry of the affiliation between HGS and BMI in an Australian population was made. The objective of this study was to describe normative data for HGS and BMI of students of TUBC and UOSP so it commenced with HFA at educational environment and a futuristic approach. The major endeavor was to develop the HFA attitude of student communities and expand the environment of health consciousness in the public. The investigation has been conducted to create an environment of fitness assessment and develop fresh data for the comparison of health and fitness assessment of student community of two universities and expand it to the health and fitness assessment of two nations i.e. Pakistan and China.

\section{Results}

There were 600 students of TUBC and UOSP who participated during 2012. Both male and female students were distributed in equal half of 150 male and 150 female students of an age group of 18 to 23 years from both universities. The study population was relatively young and they were classified into three gender groups. The BMI and HGS comparison of TUBC and UOSP arranged as M v/s M and F v/s F and MF v/s MF. The $50 \%$ percent of each group participated in both assessments and both genders compared separately. The comparison of weight mean values and standard deviations were of TUBC and UOSP male (72.05 - 65.24) and in female (57.47-55.45) and in combine male female (64.33 - 60.27). The std. deviations of weight of both universities males were (13.15 - 11.13)and in female $(9.54-12.02)$ and MF (13.15 - 10.66)and weight $\mathrm{t}$-value (82.49 -83.2). In height means of male were (174.01- 167.74)and female (164.29 - 157.38)and MF (169.6 162.26). The std. deviations of male students height were (6.33-9.76)and female (7.19-8.88) and $8.33-8.53$ of MF and $\mathrm{t}-$ value of TUBC 351.53 and UOSP 321.43. The BMI mean of male was $(23.72-23.34)$ and female (21.19 -22.21) and MF (22.45 - 22.77) and t- value (110.16-103.38). The mean values of hand grip strength of male $(23.72-23.34)$ and female $(21.19-22.21)$ and MF (22.45 - 22.77). The std. deviations of HGS of male was $(9.16-8.30)$ and in female (5.32 - 4.94) and in MF (38.61 - 37.18). The t- value of HGS of TUBC 62.07 and UOSP 61.73 and the $\mathrm{p}$ - value 0.001 is significant at the 0.05 level as shown in table 1 andBMI $\mathrm{r}^{2}=0.010$ in figure 4 and $\mathrm{HGS} \mathrm{r}^{2}=0.290$ figure 5.The table 2 portrayed the BMI comparison of TUBC and UOSP gender as $\mathrm{M} \mathrm{v} / \mathrm{s} \mathrm{M}$ and $\mathrm{F} \mathrm{v} / \mathrm{s} \mathrm{F}$ and $\mathrm{MF} \mathrm{v} / \mathrm{s} \mathrm{MF}$. In figure 1 specified the percentage of $\mathrm{M}$ v/s $\mathrm{M}$ of TUBC and UOSP BMI (57\% - 59\% normal, 29\% -25\% Overweight, 7\% -9\% Obese and 7\% equal in Underweight). The figure 2 quantified the $\mathrm{f} \mathrm{v} / \mathrm{s} \mathrm{f}$ comparison of both university students in BMI $77 \%-68 \%$ normal, $8 \%-21 \%$ Overweight $13 \%-7 \%$ underweight and $1 \%-4 \%$ Obese. The figure 3 illustrated overall both gender combine average of MF v/s MF as 67\% -64\% normal, $18 \%-23 \%$ overweight, $10 \%-7 \%$ underweight and $4 \%-6 \%$ obese. In HGS assessment the average performance of both universities students of (dominant hand)strength were depicted as according to the normative scale of strength evaluation of franklin 2000. In figure 3 highlighted the physiological response of dominant hand strength performance. The HGS of TUBC and UOSP male students were $20 \%-20 \%$ VP, $21 \%-20 \%$ Poor, $18 \%-23 \%$ below average. and Av, 9\%-15\% AB. Av. $7 \%-5 \%$ Good 5\%$1 \%$ Excellent. In female 1\% - 2\% VP 3\% -1\% poor, 14\% -28\% below average, $29 \%-27 \%$ Av, $33 \%-28 \%$ above average . 11\% - 9\%Good and 10\% - 6\% Excellent. The overall male and female of both universities average 10\%-11\% VP, $12 \%$ - 10\% poor, 16\%-25\% below average., 25\%-21\% Av., 21\% Ab. Av., similarly, $9 \%-7 \%$ Good and $7 \%-4 \%$ Excellent.

\section{Discussion}

Physical fitness is ultimate need of public health. Recently endeavored to develop an attitude of young adolescence of global population to involve and keep physically healthy and fit by mean of health and fitness 
activities. Epidemiological studies of the past 4 decades have clearly demonstrated the vitality of physical activities and its impact of reduction of mortality and morbidity. (Paffenbarger, Wing, Hyde, Hsieh1986, 1980, $1978)^{20}$ This has an influence on the risks of morbidity and mortality and therefore can reduce these risks. Disease prevention and health promotion should be implemented as early as possible in both childhood and adolescence. The study indicated that $18-23$ years of age of Female BMI normal ratio is higher than male and male overweight and obese ratio is higher than female, however the underweight ratio of female is higher than male. Some studies indicated that underweight people have a higher than normal risk for premature death. Though the adequate evidence shows extreme leanness (e.g. anorexia nervosa can be life threatening). The underweight individuals may have lost weight because of medical condition too (Corbin, 2008) ${ }^{21}$. The experts agreed that no less than 5\%t male and $10 \%$ female have an exceptionally low body fat percentage. Due to low fat percentage among female the amenorrhea may occur and along with amenorrhea such females are also at risk of bone loss such as osteoporosis. The study indicated that 10\% TUBC and 7\% UOSP students are underweight and might be at risk of these problems. The BMI $>25$ and less than $<30$ was exposed among bilaterally UOSP higher than TUBC students participants of the prevalence of body fat ratio greater than considered as overweight. Overall overweight and obesity of UOSP students was higher than TUBC students. It is also an alarming condition for young learning students of both universities. As the overweight conditions cause certain diseases and medical complications with risks of heart disease, high blood pressure, blood lipids and sedentary living ( Welk, 2008). ${ }^{22}$ The healthy range of body fat in males is $10 \%$ to $20 \%$ percent while in females it is $17 \%$ to $28 \%$ t. These levels are associated with good metabolic fitness, good health and wellness. As per results, $23 \%$ of UOSP and $18 \%$ of TUBC students are overweight and at high risk of these health problem. With concern to HGS values, the performances of both university students were satisfactory. The observations of attitude of TUBC students towards healthy activities were encouraging and positive as compared to UOSP students. The results of t- value displayed significant differences in BMI and strength, between TUBC and UOSP students, where TUBC students were found more active and involved in health and fitness than their counterparts. The correlation of TUBC BMI and UOSP HGS is at the 0.01 and UOSP BMI and TUBC HGS is at 0.05 level (2tailed). A similar type of results were obtained in the study of Mehtap and Nihal $(2005)^{23}$ who conducted a study on physical fitness in rural children compared with urban children in Turkey and found that children living in the urban areas were more inactive and obese than rural children. The recent studies also indicated a significantly increased risk of various kinds of cancer, high blood pressure, asthma, back pain, osteoarthritis, liver disease, and pulmonary disease; pancreatitis and gallbladder problems associated with obesity (Corbin, 2008). ${ }^{24}$ The higher incidence of certain diseases and other health problems indicate that people who are moderately over fat level have 40 percent higher than normal risk of shortening their life span (Welk, 2008$)^{25}$. More severe obesity results in a $70 \%$ higher than normal death rate. Obese segment is red zone for health risk and physical conditions. In this study portrayed that $9 \%$ UOSP and 7\% TUBC male and $4 \%$ UOSP and $1 \%$ TUBC female and overall both gender $6 \%$ UOSP and $4 \%$ TUBC at high risk of obesity were indicated at red zone among young students. They were at great threat, facing back pain, asthma, osteoarthritis and other problems. The results were also elaborated that TUBC female students more conscious about maintaining their weight and physical and physiological status of physique then UOSP females students. On the other end, the HGS the female dominant hand grip performance was higher than UOSP female as compared to male female attitude of performance were highly positive. In view of HGS performance according to the normative scale, the TUBC students of both genders give recovering performance as compared to UOSP students, the major impediments are availability of health facilities and, environment of physical activities and sports. Instead UOSP students have unavailability of facilities and environment of health and fitness activities in their routine. It is main intention of health and fitness differences in UOSP students.

\section{Conclusion}

The purpose of the investigation here was to develop an attitude of self-health appraisal and consciousness/awareness in student's communities and assessed their fitness status. The study innovative was encouraging and the subject participant's attitudes toward the health and fitness assessment activities were positive. The result highlights the strength and weakness of said age group and develops normative data for future research. The original research regarding health and fitness should create an atmosphere of general health assessment and identify the strength and weakness. Improve their physical and physiological competencies and develop an attitude to keep themselves healthy and foster and active in their routine lifestyle. The Overall goal of our research study is to benefit the general public particularly the university students.

\section{Acknowledgements:}

This study received partial financial support from Tsinghua University Beijing China to an innovation of this partial support research project in between two universities TUB China and UOS Pakistan of HFA 
issue. The authors also wish to thank both university students for their participation in this study, and the Tsinghua University Beijing for its grant that enabled this study for further collaboration of research programs.

${ }^{1}$ Gruber AJ, Pope HG Jr, L .alonde JK \& Hudson JI (2001) Why do young women diet? The roles of body fat, body perception, and body ideal. J Clinical Psychiatry 62, 609-611. Grundy SM. Multifactorial causation of obesity: Implications for prevention. Am J ClinicalNutria. 1998; 67(3 Supply):563S-572S.Kitano T, Kitano N,

\section{References}

[1]. Inomoto T \&Futatsuka M (2001) Evaluation of body composition using dual-energy X-ray absorptiometry, skinfold thickness and bioelectrical impedance analysis in Japanese female college students. J NutrSciVitaminol (Tokyo) 47, 122-125.

[2]. World Health Organization (1995) Physical Status: the Use and Interpretation of Anthropometry.Technical Report Series no. 854. Geneva: WHO. World Health Organization (1998) Program of Nutrition, Family and Reproductive Health.Obesity. Preventing and Managing the Global Epidemic. Report of a WHO Consultation on Obesity. Geneva, 3-5 June 1997, Geneva: WHO.

[3]. WHO.World Health Organization (1998) Program of Nutrition, Family and Reproductive Health.Obesity. Preventing and Managing the Global Epidemic. Report of a WHO Consultation on Obesity. Geneva, 3-5 June 1997, Geneva: WHO.

[4]. James, P. T., Rigby, N. and Leach, R. International Obesity Task Force. The obesity epidemic, metabolicsyndrome and future prevention strategies. Eur. J.Cardiovasc. Prev. Rehabil. 2001, 11: 3-8

[5]. Kopelman, P. G. Obesity as a medical problem. Nature 2000, 404:635-643

[6]. http://www.chinadaily.com.cn/china/201308/06/content_16872842.htm 2013/10/7:13:34pm pg.1

[7]. Bhanji S, Khuwaja AK, Siddiqui F, Azam I, Kazmi K. Underestimation of weight and its associated factors among overweight and obese adults in Pakistan: a cross sectional study. BMC Public Health. May 23 2011;11(1):363.

[8]. Lemon SC, Rosal MC, Zapka J, Borg A, Andersen V. Contributions of weight perceptions to weight loss attempts: differences by body mass index and gender. Body Image. Mar 2009;6(2):90-96

[9]. Era P, Rantanen T, Avlund K, et al. Maximal isometric muscle strength and anthropometry in 75-year-old men and women in threeNordic localities. Scand J Med Sci Sport. 1994;4:26-31. Rantanen T, Masaki K, Foley D, Izmirlian G, White L, GuralnikJM.Grip strength changes over 27 years in Japanese-American men. JAppl Physiol. 1998;85:2047-2053.

[10]. Bernard S, LeBlac P, Whittom F, et al. Peripheral muscle weakness in patients with chronic obstructive pulmonary disease. Am $J$ RespirCritCare Med. 1998;158:629-634., Häkkinen A, Hannonen P, Häkkinen K. Muscle strength in healthy people and inpatients suffering from recent-onset inflammatory arthritis. Br J Rheumatol. 1995;34:355-360.

[11]. Rantanen T, Parkatti T, Heikkinen E. Muscle strength according to level of physical exercise and educational background in middle-aged women in Finland. Eur J Appl Physiol. 1992;65:507-512.

[12]. Kaplan GA, Seeman TE, Cohen RD, Knudsen LP, Guralnik J. Mortality among the elderly in Alameda County study.Am J Public Health. 1989;79:703-708

[13]. Phillips P. Grip strength, mental performance and nutritional status as indicators of mortality risk among female geriatric patients. Age Ageing. 1986;15:53-56. 10. Rantanen T, Era P, Heikkinen E. Physical activity and the changes in maximal isometric strength in men and women from the age of 75 to 80 years. J Am Geriatr Soc. 1997;45:1439-1445.

[14]. Fujita Y, Nakamura Y, Hiraoka J, et al. Physical-strength tests and mortality among visitors to health-promotion centers in Japan. $J$ ClinEpidemiol. 1995;48:1349-1359.

[15]. Laukkanen P, Heikkinen E, Kauppinen M. Muscle strength and mobility as predictors of survival in 75-84-year-old people. Age Ageing. 1995;24:468-473. 10. Rantanen T, Era P, Heikkinen E. Physical activity and the changes in maximal isometric strength in men and women from the age of 75 to 80 years. J Am Geriatr Soc. 1997;45:1439-1445.

[16]. Fess EE Grip strength in clinical assessment recommendations $2^{\text {nd }}$ edition Edited by Casanova JS. Chicago American Society of Hand Therapists 1992,41 -45

[17]. Mathiowetz . M comparion of Rolvan and Jamar dynamometers for measuring grip strength, Occtherint, 2002,9: 301-209. Publisher full text

[18]. Schmidt N, van der Windt D, Assendelft W, Mourits A, Deville W, de Winter A, Bouter L:Interobserver Reproducibility of the Assessment of Severity of Complaints, Grip Strength, and Pressure Pain Threshold in Patients With Lateral EpicondylitisArch Phys Med.Rehabil2002,83:1145-50 PubMed Abstract | Publisher Full Text

[19]. Angst F, Drerup S, Werle S, Herren DB, Simmen BR, Goldhahn J: Prediction of grip and key pinch strength in 978 healthy

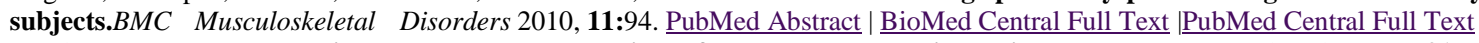
8.Bohannon RW: Hand-grip dynamometry predicts future outcomes in aging adults.JGeriatrPhysTher 2008,31:310 PubMed Abstract

[20]. Puffenbarger R.S and R.T Hyde, A. L. Wing 1986, 1980, 1978, Exercise protection against Heart attack, Physical Activity, all caused of mortality and longevity of college alumni , New England journal of Medicine. 1027,613,175

[21]. Corbin, Gregory J. Welk, William R.Corbin, Karen A. Welk, Concepts of Fitness and Wellness $7^{\text {th }}$ edition 2008, New York USA, McGraw- Hill Companies Inc. pg. 78

[22]. J. Welk Charles B Corbin, Gregory J. Welk, William R.Corbin, Karen A. Welk, Concepts of Fitness and Wellness $7^{\text {th }}$ edition 2008, New York USA, McGraw- Hill Companies Inc.pg. 79

[23]. MehtapOzdirenc, NihalGelecek 2005. Physical fitness in rural children compared with urban children in Turkey. Pediatrics International, 47(1): 26-31.

[24]. Corbin, Gregory J. Welk, William R.Corbin, Karen A. Welk, Concepts of Fitness and Wellness $7^{\text {th }}$ edition 2008, New York USA, McGraw- Hill Companies Inc pg.79.

[25]. J. Welk Charles B Corbin, Gregory J. Welk, William R.Corbin, Karen A. Welk, Concepts of Fitness and Wellness $7^{\text {th }}$ edition 2008, New York USA, McGraw- Hill Companies Inc.pg.81 
Comparing BMI and hand grip strength of Tsinghua University Beijing and University of ...

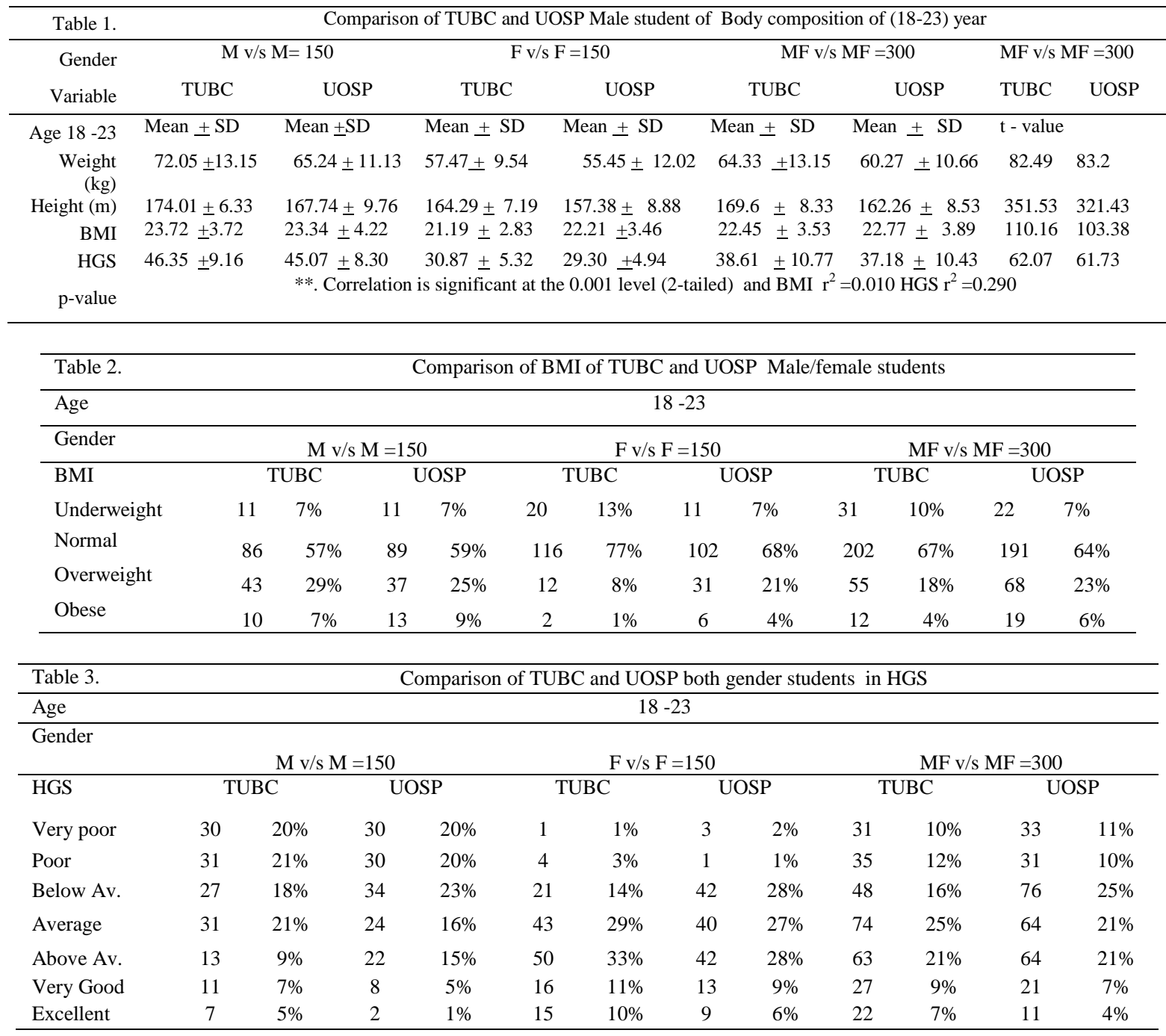

Figure 1. Comparison of TUBC and UOSP Male students BMI of 18 - 23 year of age

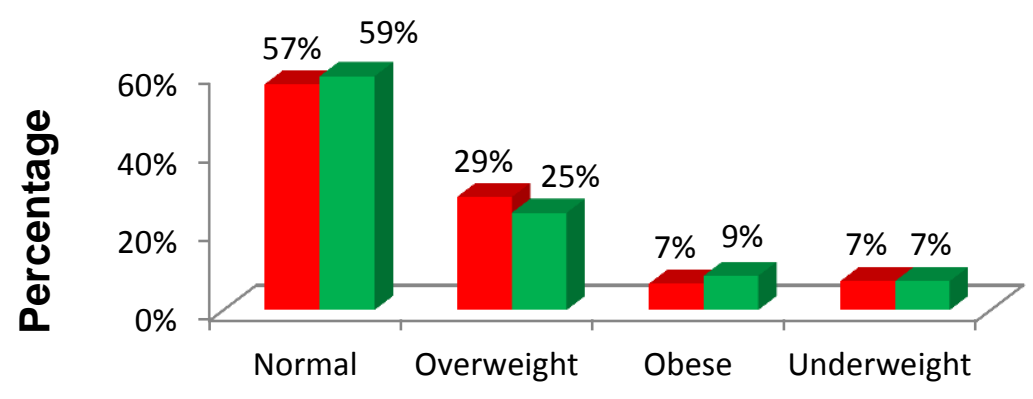

$18-23 \mathrm{M} \mathrm{v} / \mathrm{s} \mathrm{M}=150$ TUBC $\quad 18-23 \mathrm{M} \mathrm{v} / \mathrm{s} \mathrm{M}=150$ UOSP 
Figure 2. Comparison of TUBC and UOSP Female students BMI of 18 - 23 year of age

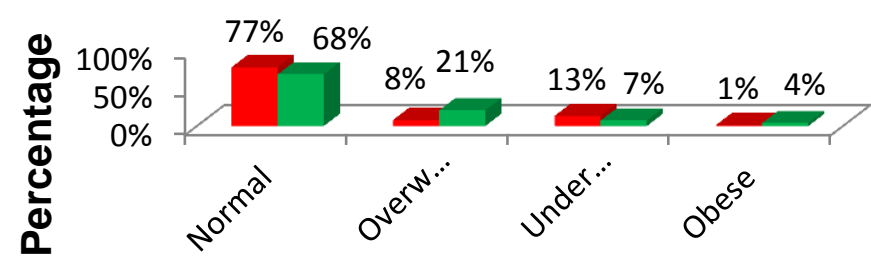

- $18-23 \mathrm{~F} \mathrm{v} / \mathrm{s} F=150$ TUBC $\quad 18-23 \mathrm{~F} \mathrm{v} / \mathrm{s} F=150$ UOSP

Figure 3. Comparison of TUBC and UOSP MF students BMI of 18 - 23 year of age

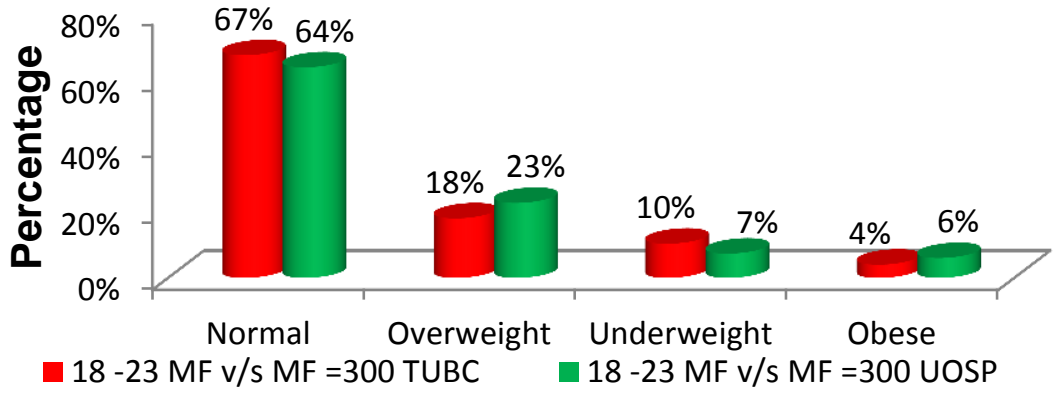

Figure 4. Comparison of TUBC and UOSP HGS of dominent hand of Male students $(18-23)$ years

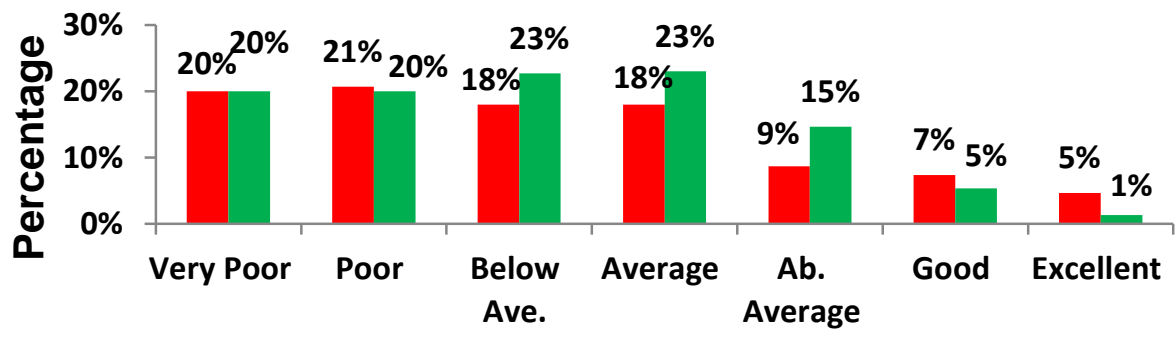

$\square 18-23 \mathrm{M} \mathrm{v} / \mathrm{s} \mathrm{M}$ TUBC $\quad 18-23 \mathrm{M} \mathrm{v} / \mathrm{s} \mathrm{M}$ UOSP

Comparison of TUBC and UOSP HGS of dominent hand of female students (18 -23) years

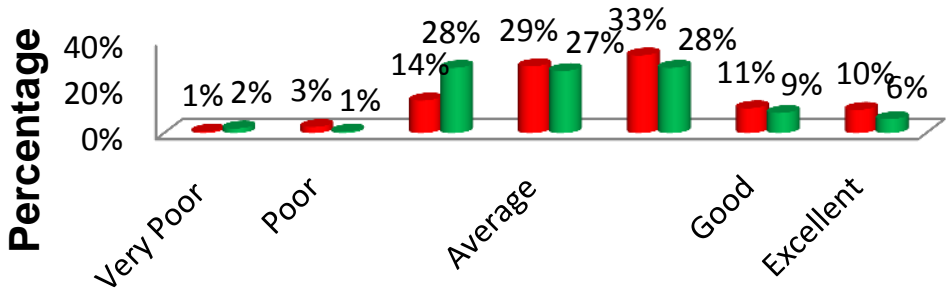

$18-23 \mathrm{Fv} / \mathrm{s}$ F TUBC $\quad 18-23 \mathrm{Fv} / \mathrm{s} \mathrm{F}$ UOSP 

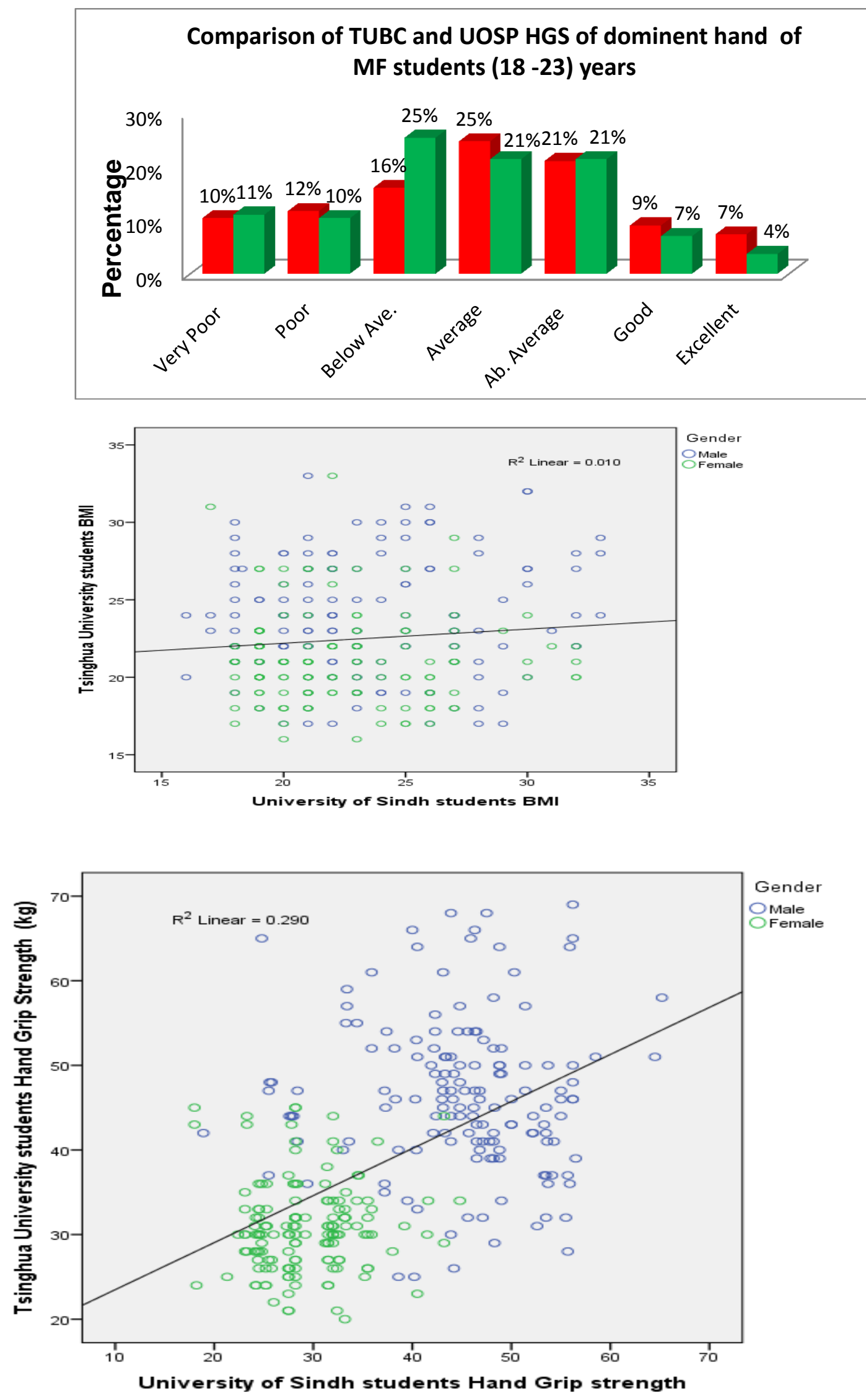
Comparing BMI and hand grip strength of Tsinghua University Beijing and University of ...

\begin{tabular}{|c|c|c|c|c|c|}
\hline \multicolumn{6}{|c|}{ Correlations } \\
\hline Variable & & TUBC (BMI) & UOSP (HGS) & TUBC (HGS) & UOSP(BMI) \\
\hline \multirow{3}{*}{ TUBC (BMI) k/hm² } & Pearson Correlation & 1 & $.249^{* *}$ & $.319^{* *}$ & .099 \\
\hline & Sig. (2-tailed) & & .000 & .000 & .088 \\
\hline & $\mathrm{N}$ & 300 & 300 & 300 & 300 \\
\hline \multirow{3}{*}{ UOSP (HGS) (kg) } & Pearson Correlation & $.249^{* *}$ & 1 & $.539^{* *}$ & .073 \\
\hline & Sig. (2-tailed) & .000 & & .000 & .205 \\
\hline & $\mathrm{N}$ & 300 & 300 & 300 & 300 \\
\hline \multirow{3}{*}{ TUBC (HGS) (kg) } & Pearson Correlation & $.319^{* *}$ & $.539^{* *}$ & 1 & $.148^{*}$ \\
\hline & Sig. (2-tailed) & .000 & .000 & & .010 \\
\hline & $\mathrm{N}$ & 300 & 300 & 300 & 300 \\
\hline \multirow{3}{*}{ UOSP(BMI) k/hm² } & Pearson Correlation & .099 & .073 & $.148^{*}$ & 1 \\
\hline & Sig. (2-tailed) & .088 & .205 & .010 & \\
\hline & $\mathrm{N}$ & 300 & 300 & 300 & 300 \\
\hline
\end{tabular}

TUBC (BMI) and UOSP (HGS) $=* *$. Correlation is significant at the 0.01 level (2-tailed).

TUBC (HGS and UOSP (BMI) $=*$. Correlation is significant at the 0.05 level (2-tailed).

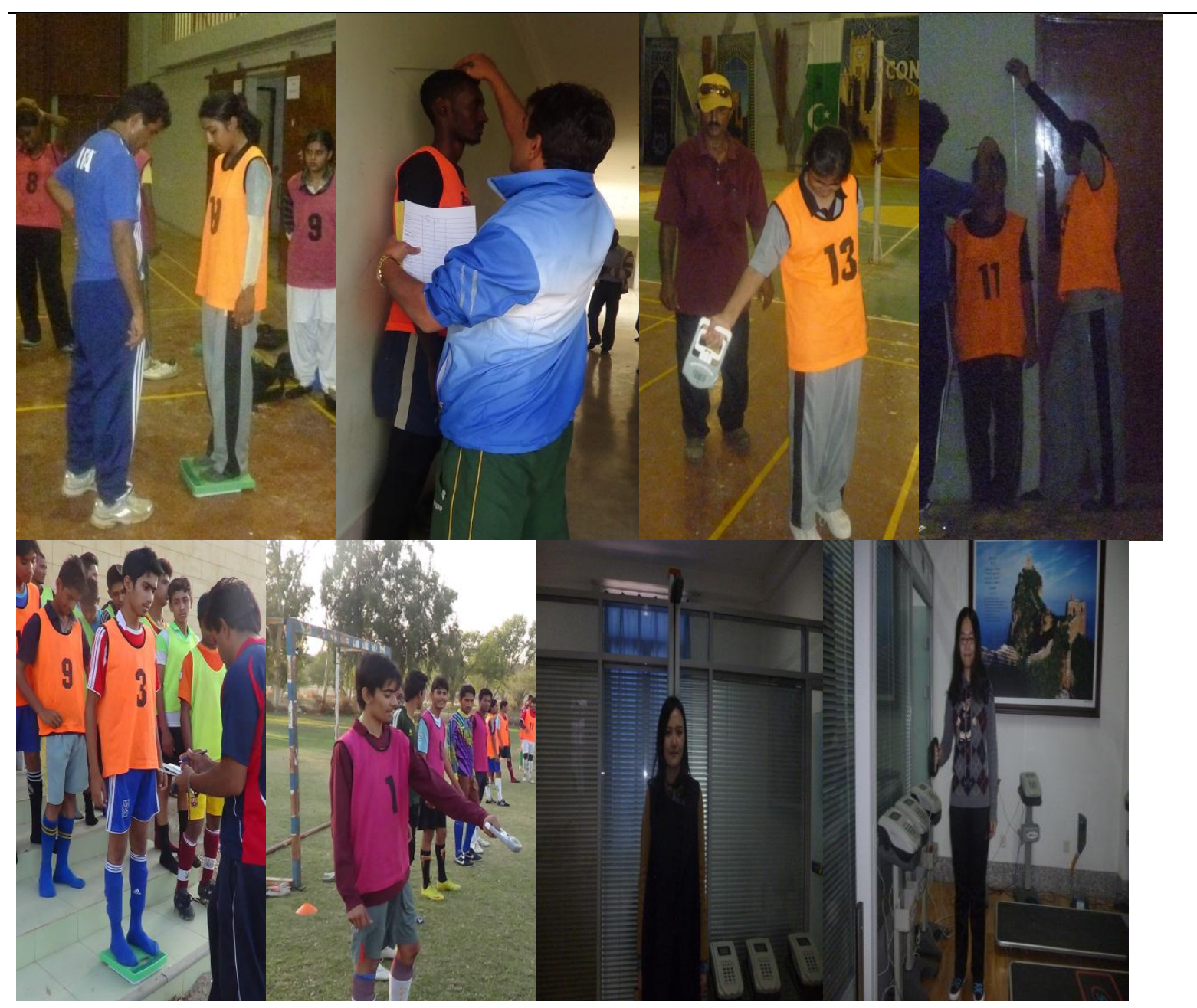

